\title{
PENINGKATAN MUTU KAYU PINUS YANG TERSERANG BLUESTAIN
}

\author{
Quality Enhancement of Pine Wood Bluestain Attacked
}

\author{
Agussalim \\ Fakultas Kehutanan Universitas Hasanuddin, ${ }^{\circledR}$ corresponding author: agussalim.madjid@yahoo.co.id
}

\begin{abstract}
One of the many problems of pine wood as furniture raw material is bluestain attack. The purpose of this research was to improve the quality appearance of pine wood by using oil and heat treatments. Materials used in this study consist of four attack levels of pine wood, namely heavy, moderate, mild and no attack. Oil heat treatment condition was $200^{\circ} \mathrm{C}$ for 1 and 2 hours, while heat treatment condition was $170^{\circ} \mathrm{C}, 185^{\circ} \mathrm{C}$ and $200^{\circ} \mathrm{C}$ for 1 and 2 hours. Eight treatments had been applied for this research with three replicas. The result of this study indicates that pine wood for any treatment using oil heat treatment is darker compared to control, so the bluestain is less apparent. Meanwhile, heat treatment has no effect to improve the quality appearance.
\end{abstract}

Key words: Pinus merkusii, bluestain, quality enhancement, oil heat treatment, heat treatment

\section{A. PENDAHULUAN}

Serangan jamur dapat menyebabkan terjadinya pembusukan, pelunakan dan atau pewarnaan pada kayu (Bowyer et al, 2003). Hal ini dapat menurunkan mutu kekuatan serta mutu penampilan dari sebuah kayu. Serangan jamur dapat terjadi apabila tiga komponen yakni air, oksigen serta sumber nutrien terpenuhi dalam jumlah yang cukup di dalam kayu (Hill, 2006).

Pewarnaan pada kayu diakibatkan oleh jamur dari kelas Ascomycetes atau Deuteromycetes. Jamur ini tumbuh di permukaan atau dalam rongga sel, terutama pada parenkim jari-jari. Pigmen hifa jamur pewarna memberikan warna kebiru-biruan atau kehitam-hitaman (Bowyer et al, 2003). Perubahan warna yang terjadi pada pemukaan kayu dapat menutupi seluruh permukaan kayu atau berupa bintik, spot-spot, garis, ataupun tambalantambalan dengan intesitas pewarnaan yang bervariasi (Forest Product Laboratory, 1999)

Pewarnaan oleh jamur menjadi masalah utama untuk penggunaan kayu sebagai bahan baku meubel, terutama produk meubel yang ingin menampilkan warna serta corak alami. Kayu pinus selama ini dikenal sebagai bahan baku meubel yang menarik dari segi warna dan coraknya. Namun di sisi yang lain, pinus sangat rentan terserang bluestain dikarenakan permeabilitasnya yang tinggi yang memungkinkan jamur dapat berkembang dengan baik. Akibatnya, pinus dapat mengalami pewarnaan yang merusak mutu penampilan kayu.

Selama ini telah banyak dilakukan upaya-upaya dalam meningkatkan mutu kayu dari segi kekuatan, penampilan, stablitas dimensi dan keawetannya. Beberapa modifikasi yang dilakukan terhadap kayu

Diterima: 24 Januari 2018; Disetuiui: 20 Maret 2018 meliputi modifikasi pemanasan (densifikasi, perlakuan oil heat), modifikasi permukaan, modifikasi impregnasi (Hill, 2006).

Beberapa cara yang dapat dilakukan dalam meningkatkan mutu penampilan dari kayu terserang bluestain adalah dengan perlakuan oil heat dan pemanasan. Perlakuan tersebut akan memberikan perubahan warna pada kayu, sehingga diharapkan mampu menghilangkan pewarnaan yang diakibatkan oleh bluestain. Oleh karena itu, penelitian ini bertujuan untuk meningkatkan mutu kayu pinus yang terserang bluestain melalui perlakuan oil heat dan pemanasan.

\section{B. BAHAN DAN METODE}

Contoh uji yang digunakan berupa kayu pinus (Pinus merkusii) yang terserang jamur bluestain dengan tingkat serangan ringan, sedang, berat dan tanpa terserang, dimana tingkat serangan jamur ditentukan melalui kepekatan pewarnaan yang dihasilkannya. Contoh uji berukuran panjang $10 \mathrm{~cm}$, lebar $5 \mathrm{~cm}$ dan tebal $2 \mathrm{~cm}$. Untuk perlakuan oil heat digunakan minyak goreng curah. Sedangkan alat yang digunakan dalam penelitian ini adalah Universal Testing Machine (UTM), caliper, oven, kotak kedap udara untuk pengujian $\mathrm{RH}$, higrosmeter, dan timbangan.

Semua contoh uji terlebih dahulu dikeringkan bertahap sebelum dilakukan perlakuan untuk menghindari terjadinya retak akibat pemanasan pada suhu tinggi. Pemanasan bertahap dilakukan pada suhu $60^{\circ} \mathrm{C}, 80^{\circ} \mathrm{C}$ dan $100^{\circ} \mathrm{C}$. Pengukuran berat kering oven $\left(B_{k o}\right)$ dilakukan setelah pemanasan pada suhu $100^{\circ} \mathrm{C}$. Setelah itu, contoh uji pemanasan dikeringkan pada oven dengan suhu $170^{\circ} \mathrm{C}, 185^{\circ} \mathrm{C}$ dan $200^{\circ} \mathrm{C}$, masing-masing 1 dan 2 jam. 
Sedangkan, contoh uji untuk perlakuan oil heat dipanaskan menggunakan minyak goreng curah dengan suhu $200^{\circ} \mathrm{C}$ selama 1 dan 2 jam. Setelah perlakuan pemanasan dan oil heat selesai, contoh uji kemudian dikeringkan kembali pada suhu $100^{\circ} \mathrm{C}$ untuk memperoleh berat kering oven setelah perlakuan ( $\left.\mathrm{B}_{\mathrm{ko}-\mathrm{p}}\right)$.

Semua contoh uji dikondisikan di udara terbuka sampai beratnya tetap dan didapatkan berat kering udara (Bku-p). Selanjutnya contoh uji dimasukkan dalam kotak kedap udara untuk dikondisikan pada $\mathrm{RH} 58 \%$. Setelah $\mathrm{RH}$ yang diinginkan dicapai, contoh uji kemudian ditimbang dan diperoleh berat pada $\mathrm{RH} 58 \%$ (B $\mathrm{B}_{\mathrm{RH}-\mathrm{P}}$ ).

Pengaruh perlakuan terhadap penampilan permukaan kayu pinus diamati secara visual, sedangkan untuk melihat pengaruh perlakuan terhadap sifat kayu dilakukan perhitungan laju penurunan kadar air (LPKA), kehilangan berat (WL) pada perlakuan pemanasan dan penambahan berat pada perlakuan oil heat (WG). Hasil yang diperoleh dianalisis secara deskriptif.

$$
\begin{aligned}
& \mathrm{LPKA}=\left(\mathrm{K} A_{K U-P}-K A_{R H 58}\right) /\left(\mathrm{RH}_{K U-P}-\mathrm{RH}_{\mathrm{RH}-\mathrm{P}}\right) \\
& W L=\left(B_{k 0}-B_{k o-P}\right) / B_{k o} \times 100 \% \\
& W G=\left(B_{k 0}-p-B_{k 0}\right) / B_{k O} \times 100 \%
\end{aligned}
$$

\section{HASIL DAN PEMBAHASAN}

Perubahan warna yang dialami kayu pinus terserang bluestain yang memperoleh perlakuan oil heat dan pemanasan dapat dilihat pada Gambar 1 dan 2.

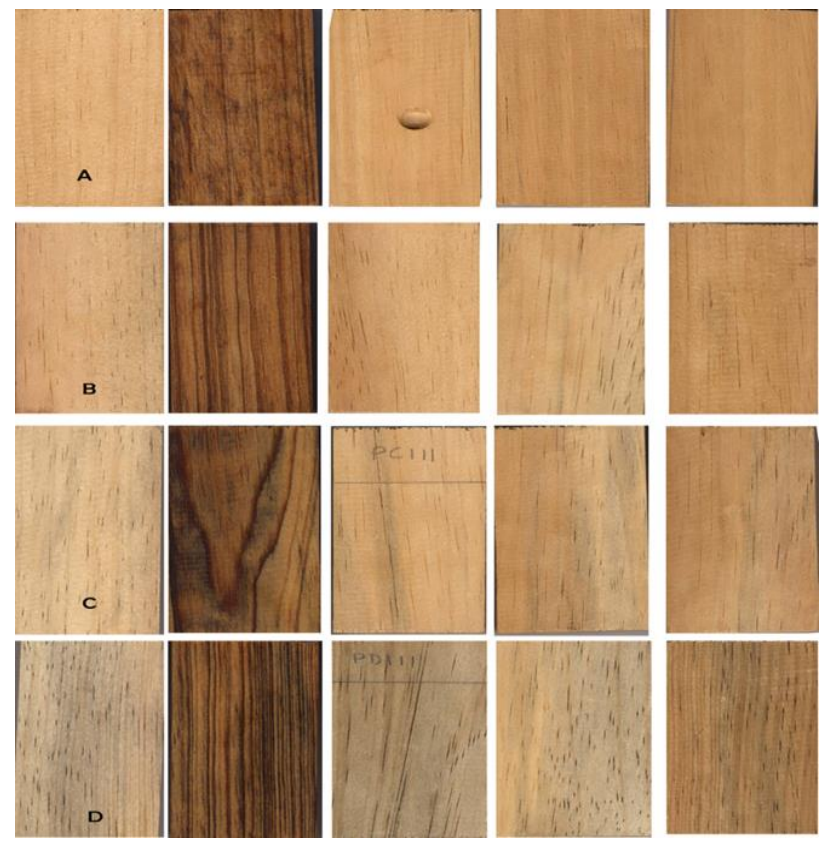

Gambar 1. Kontrol dan kayu pinus yang telah diberi perlakuan oil heat dan pemanasan selama 1 jam. Baris $A, B$, $C$ dan $D$ masing-masing tanpa serangan, ringan, sedang, dan berat, sedangkan kolom dari kiri ke kanan yakni kontrol, oil heat, pemanasan $170^{\circ} \mathrm{C}$, $185^{\circ} \mathrm{C}$ dan $200^{\circ} \mathrm{C}$
Warna kayu pinus dengan perlakuan oil heat menjadi lebih menarik dengan makin jelasnya pola serat yang ditampilkan berupa garis-garis tegas serta penampilan kayu lebih berkilap. Jika diperhatikan dari segi warna yang ditampilkan, maka oil heat selama 1 dan 2 jam tidak menunjukkan perbedaan.

Terhadap serangan bluestain, perlakuan oil heat tidak menghilangkan bluestain pada kayu namun membuat warna kayu menjadi agak gelap sehingga bluestain tersamarkan. Hal tersebut nampak pada kayu pinus dengan tingkat serangan berat dimana bluestain terlihat samar. Demikian pula halnya dengan kayu dengan tingkat serangan sedang. Sedangkan, kayu dengan tingkat serangan rendah bluestain tidak terlihat karena intensitas serangan bluestainnya memang rendah.

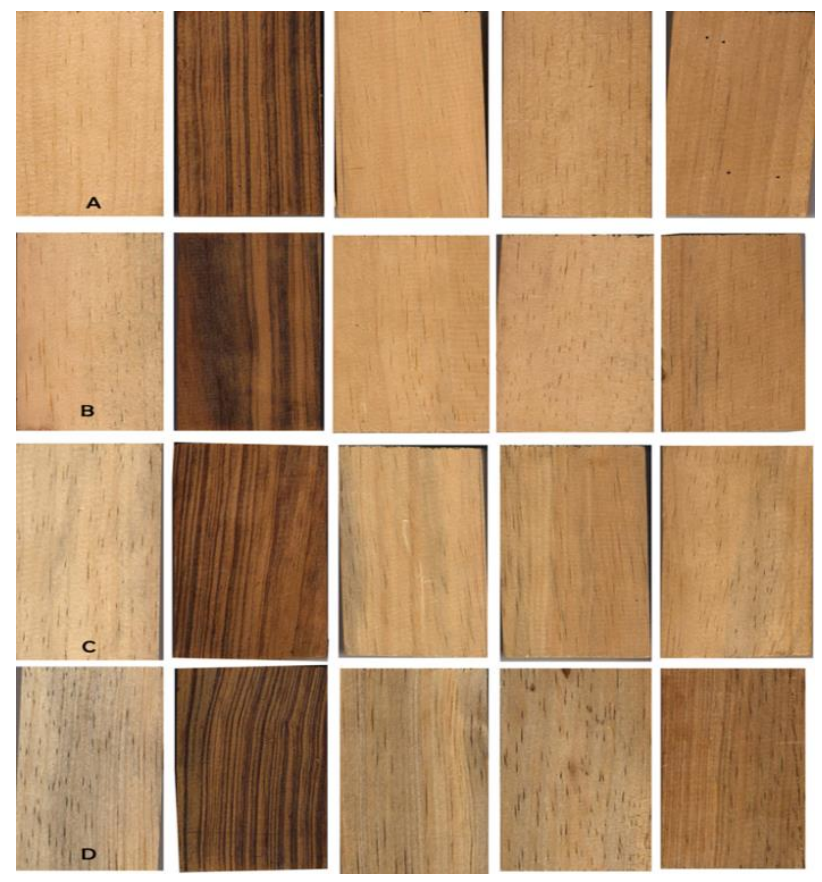

Gambar 2. Kontrol dan kayu pinus yang telah diberi perlakuan oil heat dan pemanasan selama 2 jam. Baris $A, B$, $C$ dab $D$ masing-masing tanpa serangan, ringan, Sedang, dan berat, sedang kolom dari kiri ke kanan yakni kontrol, oil heat, pemanasan udara $170^{\circ} \mathrm{C}, 185^{\circ} \mathrm{C}$ dan $200^{\circ} \mathrm{C}$

Respon yang berbeda ditunjukkan pada perlakuan pemanasan dimana bluestain masih nampak terlihat dengan jelas pada tingkat serangan ringan, sedang dan berat. Meskipun terjadi perubahan warna menjadi gelap terjadi pada perlakuan pemanasan pada suhu $200^{\circ} \mathrm{C}$, namun bluestain masih dapat terlihat dengan jelas.

Perlakuan oil heat mengakibatkan peningkatan berat kayu dari $31.91 \%$ hingga mencapai $104.94 \%$. Kayu yang dengan perlakuan oil heat mengalami peningkatan berat $50-70 \%$ (Hill, 2006). Peningkatan berat kayu paling besar terjadi pada kayu pinus yang tidak terserang bluestain dan menurun hingga tingkat serangan berat. Kayu dengan 


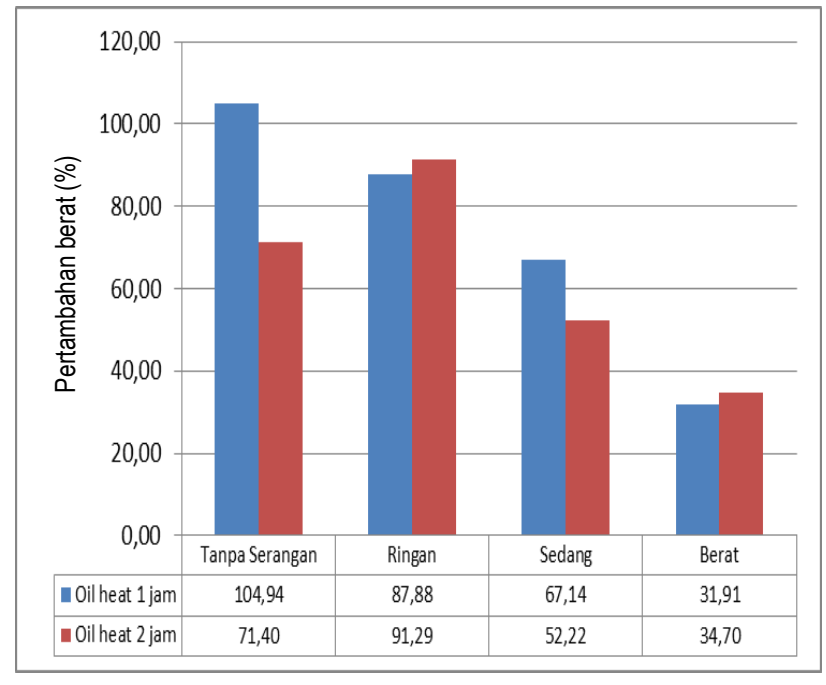

Gambar 3. Penambahan berat (\%) pada perlakuan oil heat

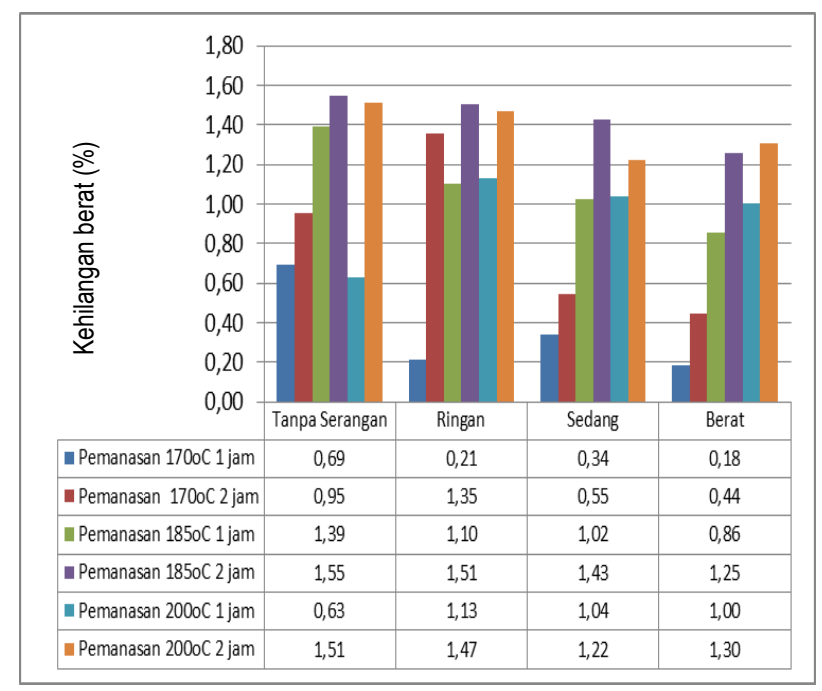

Gambar 4. Kehilangan berat (\%) pada perlakuan pemanasan

\begin{tabular}{|c|c|c|c|c|}
\hline \multirow{9}{*}{ 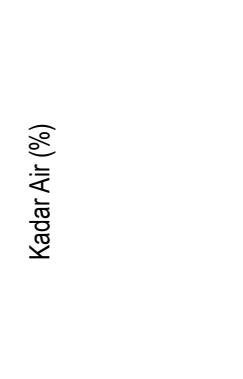 } & & & & \\
\hline & & & & \\
\hline & & & & \\
\hline & & & & \\
\hline & & & & \\
\hline & & & & \\
\hline & & & & \\
\hline & & & & \\
\hline & Tanpa Serangan & Ringan & Sedang & Berat \\
\hline Kontrol & 0,25 & 0,21 & 0,19 & 0,24 \\
\hline Oil heat $1 \mathrm{jam}$ & 0,12 & 0,06 & 0,08 & 0,11 \\
\hline Oil heat 2 jam & 0,06 & 0,04 & 0,06 & 0,07 \\
\hline Pemanasan $1700 \mathrm{C} 1 \mathrm{jam}$ & 0,29 & 0,36 & 0,31 & 0,31 \\
\hline Pemanasan $1700 \mathrm{C} 2 \mathrm{jam}$ & 0,27 & 0,31 & 0,31 & 0,29 \\
\hline Pemanasan $185 \circ \mathrm{oC} 1 \mathrm{jam}$ & 0,28 & 0,33 & 0,32 & 0,33 \\
\hline Pemanasan $1850 \mathrm{C} 2 \mathrm{jam}$ & 0,31 & 0,33 & 0,31 & 0,29 \\
\hline Pemanasan $200 \circ \mathrm{C} 1 \mathrm{jam}$ & 0,23 & 0,26 & 0,31 & 0,20 \\
\hline Pemanasan $2000 \mathrm{C} 2 \mathrm{jam}$ & 0,23 & 0,24 & 0,19 & 0,14 \\
\hline
\end{tabular}

Gambar 5. Laju penurunan kadar air (\%)

tingkat serangan berat menghasilkan respon penambahan berat yang paling kecil baik pada lama perlakuan 1 jam maupun 2 jam. Hifa-hifa jamur yang memenuhi ruang-ruang pada sel-sel kayu pinus diduga menjadi faktor penghambat masuknya minyak dalam jumlah yang lebih banyak ke dalam kayu.

Jamur pada mulanya hanya berada pada jari-jari kayu gubal. Hifa kemudian melakukan penetrasi ke dalam dinding sel parenkim jari-jari dan kemudian berkembang biak di dalamnya. Hifa juga tumbuh secara bebas di daerah lamella tengah jari-jari. Pada akhirnya, hifa masuk ke dalam trakeid melalui noktah setengah berhalaman. Di dalam trakeid hifa tumbuh secara longitudinal, lalu hifa melewati trakeid satu menuju trakeid lainnya melalui noktah berhalaman (Ballard et al, 1984)
Sementara pada perlakuan pemanasan, kehilangan berat terkecil terjadi pada kayu pinus dengan tingkat serangan berat (Gambar 4). Hal ini diduga karena kayu telah mengalami kehilangan berat sebelumnya saat kayu tersebut terserang jamur. Jamur pewarna memanfaatkan gula dan pati (zat ekstraktif) pada sel parenkim jari-jari kayu gubal sebagai sumber makanan (Bowyer et al, 2003). Maka zat ekstraktif yang bersisa pada kayu yang terserang jamur dengan tingkat serangan berat relatif lebih sedikit dibanding dengan kayu pada tingkat serangan sedang, rendah, maupun tanpa serangan. Pada saat pemanasan zat ekstraktif diketahui ikut keluar dari dalam kayu dan rendahnya jumlah zat ekstraktif dalam kayu memberikan andil dalam hal kecilnya kehilangan berat pada kayu. 
Dari segi pengaruh waktu dan suhu diketahui kehilangan berat terbesar terjadi pada contoh uji dengan pemanasan 2 jam pada suhu $185^{\circ} \mathrm{C}$ dan $200^{\circ} \mathrm{C}$.

Laju penurunan kadar air seperti yang tercantum pada Gambar 5 menunjukkan bahwa pada kayu pinus dengan perlakuan oil heat mengalami LPKA yang lebih kecil dibanding perlakuan pemanasan maupun kontrol. Hal tersebut terjadi akibat kayu pinus dengan perlakuan oil heat memiliki kandungan minyak yang tinggi bersifat hidrofobik, sehingga higroskopisitasnya dalam menyerap dan melepaskan air menurun. Respon yang berbeda ditunjukkan pada contoh uji dengan perlakuan pemanasan.

\section{KESIMPULAN}

Perlakuan oil heat mampu memperbaiki warna kayu pinus yang terserang bluestain sehingga mutu penampilannya menjadi lebih baik. Warna kayu berubah menjadi lebih berkilap dan pada kayu nampak pula pola serat berupa garis-garis tegas menyerupai lingkaran tahun. Selain itu, kayu pinus dengan perlakuan oil heat pada tingkat serangan berat mengalami penambahan berat yang paling kecil yakni berkisar $30 \%$. Sedangkan, perlakuan pemanasan tidak mampu memperbaiki mutu penampilan kayu pinus di mana bluestain masih terlihat jelas.

\section{E. UCAPAN TERIMA KASIH}

Penulis mengucapkan terima kasih kepada Zahrial Coto atas segala bantuan dan masukan yang diberikan selama penelitian.

\section{F. DAFTAR PUSTAKA}

Ballard R. G., M. A. Walsh, dan W. E. Cole. 1984. The Penetration and Hrowth of Bluestain Fungi in The Sapwood of Lodgepole Pine Attacked by Mountain Pine Beetle. Can. J. Bot. 62(8): 17241729

Bowyer, J. L., R. Shmulsky, and J. G. Haygreen. Forest Products and Wood Science: An Introduction. Four Edition. lowa state Press, lowa, United States of America.

Forest Products Laboratory. 1999. Wood Handbook: Wood as an Engineering Material. Department of Agriculture, Forest Service, Forest Products Laboratory, Wisconsin, United States of America.

Hill, Callum. 2006. Wood Modification : Chemical, Thermal and Other Proses. Willey, United States of America. 